\title{
Denver X-ray conference comments and reflections on current issue of Powder Diffraction Journal (PDJ)
}

\section{August 2018}

I had the pleasure of attending the August 6-10, 2018 Denver X-ray Conference in Westminster, Colorado. The breadth and quality of the presentations were quite high and the exhibitors' hall was fully packed with booths showing XRD- and XRF-related state-of-the-art detectors, instruments, software, resources, publishers, and supplies. The conference covered the first full week of August and consisted of 16 halfday, high-quality workshops, Monday and Tuesday evening posters, an excellent Plenary session titled "Minerals and Gems", and then 15 oral session running through Friday morning. The proximity to the Rocky Mountains enabled enjoying hiking in the mountains after the conference. Further details can be read about in the conference summary included in this issue of Powder Diffraction Journal (PDJ).

This is the fourth quarterly issue of PDJ for 2018. This issue is filled with a very diverse and interesting set of papers. I believe you will find this issue has valuable content and that it is well worth reading each paper.

The first Technical Article by Mendenhall addresses the fundamental issue of Poisson statistics and difference from the widely used approximation of Gaussian statistics as related to powder diffraction patterns and weighting in numerical analysis methods such as Rietveld refinement of the atomic structure. Proper weighting of the measured intensity measurements is of significant importance when fitting a model to the observed data. Further, while computers continue to get faster and faster, the proper methodology of rebinning and the potential for reducing computer processing time without significant impact on the quality of the refinement is of particular interest. The paper shows that in cases where in situ studies are being analyzed, perhaps where tens to hundreds of different data sets are being analyzed, a theoretically valid way to rebin the measured data and properly determine the weighting of the rebinned data could make a major impact on processing time for analysis of such in situ studies.

The second article, a very interesting Technical Article, by Cavallo and Pascual, presents the results from their PXRD analysis of nearly 100 samples from the 17 th Century Pharmacy (Spenzieria) Santa Maria della Scalla in Rome, Italy. Nearly 100 samples of minerals were analyzed. While further work to characterize additional samples is ongoing the analysis of the mineral-based samples was very interesting and provides insights into the pharmacological knowledge, trade routes, and samples used in the recent centuries in Rome.
The third paper describes the synchrotron and laboratory XRD studies of double perovskites $\mathrm{Sr}_{2} \mathrm{RNbO}_{6}$ where $\mathrm{R}=$ Sm, Gd, Dy, Ho, Y, Tm and Lu by W. Wong-Ng, et al. The well known "lanthanide contraction" was again observed. Reference patterns for the series of patterns were submitted for inclusion in the Powder Diffraction File (PDF).

The fourth Technical Article is a very interesting in situ, synchrotron XRD study by K. Peterson, P. Heaney and J. Post of the hydrothermal precipitation of akaganeite $(\beta-\mathrm{FeOOH})$ and its transformation to hematite $\left(\mathrm{Fe}_{2} \mathrm{O}_{3}\right)$ between 100 and $200{ }^{\circ} \mathrm{C}$. The results of these studies suggest that the transformations describe the crystallographic/structure maturation of akaganeite and hematite in synthetic and natural hydrothermal systems.

The seven New Diffraction Data (ND) and the one Data Report (DR) papers continue the tradition of this journal to provide peer-reviewed journal publications presenting new and/or improved results for commercial and scientifically important phases. Each of the ND \& DR papers in this Issue of Powder Diffraction will lead to a new entry in the Powder Diffraction File (PDFTM) and thereby enable others to use PXRD to successfully perform phase identification and quantitative phase analysis of samples that include these new materials and to do so with great assurance that the phase ID match and QXRD analysis are correct. Particularly noteworthy is that a number of these New Diffraction Data papers report previously unavailable reference data for commercial pharmaceuticals in broad use.

In 2017 PDJ published two Supplementary issues. The first supplement was for the proceedings of the biannual EPDIC Conference (EPDIC15) held in Bari, Italy, June 2016. The second Supplementary Issue was the proceedings of the Australian X-ray Analytical Association Workshops, Conference and Exhibition held in Melbourne, Australia, February 2017th. The two proceedings Supplements contained 52 peer-reviewed technical manuscripts. We are pleased to announce that next year PDJ will once again be publishing a Special Edition of the Proceedings of the European Powder Diffraction Conference (EPDIC16).

Finally, to our readers, I look forward to your next contribution to Powder Diffraction. Submit your manuscripts for consideration of publication in PDJ to ScholarOne (https:// mc.manuscriptcentral.com/pdj).

Camden Hubbard Editor-in-Chief Powder Diffraction E-mail: camden.hubbard@me.com 